\title{
A New Model Based on 25-Hydroxyvitamin D3 for Predicting Active Crohn's Disease in Chinese Patients
}

\author{
Sinan Lin, Ying Wang, Li Li, Peng Chen, Ren Mao, Rui Feng, Yun Qiu, Yao He, Baili Chen, \\ Zhirong Zeng, Minhu Chen, and Shenghong Zhang (iD
}

Division of Gastroenterology, The First Affiliated Hospital, Sun Yat-sen University, Guangzhou, China

Correspondence should be addressed to Shenghong Zhang; shenghongzhang@163.com

Received 29 July 2018; Revised 6 October 2018; Accepted 10 October 2018; Published 16 December 2018

Academic Editor: Oleh Andrukhov

Copyright $(2018$ Sinan Lin et al. This is an open access article distributed under the Creative Commons Attribution License, which permits unrestricted use, distribution, and reproduction in any medium, provided the original work is properly cited.

\begin{abstract}
Background. The association between vitamin D3 and activity of Crohn's disease (CD) is unclear in Chinese patients. In this study, we aimed to evaluate the correlations between serum levels of 25-hydroxyvitamin D3 (25(OH)D3) and disease activity and predict active disease based on vitamin D status. Methods. Between January 2014 and December 2017, 346 CD patients from the First Affiliated Hospital of Sun Yat-sen University were recruited and categorized into a group with $25(\mathrm{OH}) \mathrm{D} 3 \leq 20 \mathrm{ng} / \mathrm{ml}$ and a group with $25(\mathrm{OH}) \mathrm{D} 3>20 \mathrm{ng} / \mathrm{ml}$. The clinical characteristics, medication, and health-care needs were compared between the groups. The correlations among $25(\mathrm{OH}) \mathrm{D} 3$ and routine serum biomarkers and disease activity were examined. The predictive efficiency of 25(OH)D3 and other biomarkers for active diseases was also explored using receiver-operating characteristic (ROC) curve analysis. A new predictive model, $-\left(5^{*} 25(\mathrm{OH}) \mathrm{D} 3+2^{*} \mathrm{Hb}\right)+\mathrm{ESR}$, and a nomogram were established using Logistic Regression. Results. Patients with $25(\mathrm{OH}) \mathrm{D} 3 \leq 20 \mathrm{ng} / \mathrm{ml}$ had higher serum levels of C-reactive protein (CRP), erythrocyte sedimentation rate (ESR), and platelets (PLT) and lower levels of hemoglobin ( $\mathrm{Hb}$ ) and albumin (ALB). Serum levels of $25(\mathrm{OH}) \mathrm{D} 3$ were inversely correlated with the score of Crohn's Disease Activity Index $(\mathrm{CDAI})\left(r_{\mathrm{s}}=-0.608\right)$. ROC analysis showed a better predictive value of $-25(\mathrm{OH}) \mathrm{D} 3$ and the new model with areas under curve (AUC) of 0.804 and 0.879 , respectively, than those of CRP (0.693) and ESR (0.713) in disease activity. A nomogram for prediction was established with a c-index of 0.882. Conclusions. Serum levels of 25(OH)D3 negatively correlated with CD activity in Chinese patients. The new model and a nomogram based on $25(\mathrm{OH}) \mathrm{D} 3$ showed a better efficiency in predicting disease activity in CD patients but warrants further study.
\end{abstract}

\section{Introduction}

Crohn's disease $(\mathrm{CD})$ is a chronic inflammatory disorder characterized by manifestations like diarrhea, abdominal distension, pain, and weight loss [1]. Although the mechanism of CD is still not fully understood, it is believed that CD is closely related to the dysfunction of the immune system including innate and adaptive immune responses. Our previous studies have shown that different kinds of cytokines are involved in the pathogenesis and development of IBD including proinflammatory miR-223 in the intestinal barrier [2] and serum interleukin-9 levels predict disease severity as well as the response to infliximab [3]. Furthermore, different immune cells such as monocytes, $\mathrm{T}$ cells, and natural killer cells (NK cells) are involved in the development of $\mathrm{CD}$ accompanied by interactions of different cytokines including interleukin-6 (IL-6) and tumor necrosis factor- $\alpha$ $(\mathrm{TNF}-\alpha)$ [4]. One of the most important immune regulators is vitamin $\mathrm{D}[5]$.

Vitamin D is a fat-soluble vitamin absorbed from dietary or cutaneous routes with multiple functions [6], which can be well measured by the level of serum 25-hydroxyvitamin D3 (25(OH)D3) [7]. As an important regulator, vitamin D is essential in CD inflammation [8], including reduction in $\mathrm{CD}^{+} \mathrm{T}$ cell proliferation, stimulation of NOD2/CARD15/ IBD1 gene expression in monocytes and epithelial cells, reduction of immune responses, and maturation of dendritic cells. Vitamin D also has regulatory effects on cytokines such as reducing production of Toll-like receptor-induced cytokines (IL-12/IL-23p40, TNF- $\alpha$, and IL-23) as well as 
increasing cytokines induced by NOD2 and TLR coactivation (IL-10 and IL-23) [9-13].

The importance of vitamin $\mathrm{D}$ in $\mathrm{CD}$ has gained attention recently. Data from a prospective cohort study including 72,719 women in the Nurses' Health Study showed that higher predictive levels of $25(\mathrm{OH}) \mathrm{D} 3$ significantly reduce the risk of $\mathrm{CD}$ but not ulcerative colitis [14]. However, another study from Europe recently demonstrated that vitamin $\mathrm{D}$ status was not associated with the risk of $\mathrm{CD}$ by the measurement of serum 25(OH)D3 but might still be limited by the relatively small sample size [15]. Although whether vitamin $\mathrm{D}$ deficiency is a risk factor for $\mathrm{CD}$ is still controversial using vitamin D status before diagnosis, previous studies have reported that the prevalence of vitamin D deficiency is much higher in CD patients than in healthy controls [16]. The correlation between vitamin D status and CD activity was first reported by Harries et al. in a cohort recruiting 40 $\mathrm{CD}$ patients [17]. In the last decade, an increasing amount of literature has been published on this topic, but no consensus has been reached. Several studies have demonstrated a negative association between 25(OH)D3 levels [18-20] and CD activity using Crohn's Disease Activity Index (CDAI) or Harvey-Bradshaw index (HBI) while other studies could not find such correlations [21-23].

Despite the increasing concerns on vitamin $\mathrm{D}$ in $\mathrm{CD}$, no studies have examined the predictive efficiency of vitamin $\mathrm{D}$ for CD activity. Besides, most previous studies were performed on patients in Western countries while only few of them showed characteristics of Chinese patients [24-26]. However, these two studies were restricted by small sample size. Further, uncertainty still exists with respect to the relationship between vitamin $\mathrm{D}$ status and $\mathrm{CD}$ disease activity in Chinese patients, and there is a need for further research.

Therefore, this study set out to determine the correlation between serum vitamin $\mathrm{D}$ levels and disease activity in Chinese people. Furthermore, we used serum 25(OH)D3 for $\mathrm{CD}$ activity prediction.

\section{Materials and Methods}

2.1. Patients. Between January 2014 and December 2017, patients diagnosed with $\mathrm{CD}$ and followed up at the First Affiliated Hospital of Sun Yat-sen University were identified. The diagnosis of $\mathrm{CD}$ was based on clinical manifestations, abdominal imaging, and intestinal pathology. A total of 346 patients with definite diagnosis and available records of $25(\mathrm{OH}) \mathrm{D} 3$ concentration in serum samples within one month before or after follow-up were included in the study. The data of these patients were extracted retrospectively from their medical records. The exclusion criteria included the absence of records on 25(OH)D3 levels or incomplete data for disease activity (CDAI or HBI). Patients with pregnancy, autoimmune diseases, irritable bowel syndrome, a history of malignancy, and ongoing infection during their first visit were also excluded. Also, no patients with any current treatment of vitamin D were included in this study.

2.2. Description of Variables. For these patients, data including gender, age, duration of the disease, previous major intestinal surgery, disease location, behavior, presence of perianal lesions, extraintestinal manifestations, and levels of serum $25(\mathrm{OH}) \mathrm{D} 3$ at the first visit were recorded. To determine the severity of disease, systemic inflammation, and nutrient status of patients, we also recorded the score of Crohn's Disease Activity Index (CDAI) or HarveyBradshaw index (HBI, when CDAI is unavailable), Simplified Endoscopic Score for Crohn's disease (SESCD, if without previous intestinal surgery), body mass index (BMI), and serum parameters like C-reactive protein (CRP), erythrocyte sedimentation rate (ESR), counts of white blood cells (WBC) and platelets (PLT), hemoglobin (Hb), and albumin (ALB) levels at the first visit. Additionally, we also recorded the time needed for abdominal imaging, IBD-related hospital admission, and IBD-related bowel surgery during follow-up.

Montreal classification was applied to the location and behavior of disease [27]. Extraintestinal manifestations included arthritis, cutaneous lesions, stomatitis, uveitis, and hepatobiliary manifestations.

The serum 25(OH)D3 levels were recorded for determining the status of vitamin D in CD patients. Levels of $\leq 20 \mathrm{ng} /$ $\mathrm{ml}$ denoted vitamin D deficiency, $20-29 \mathrm{ng} / \mathrm{ml}(20 \mathrm{ng} / \mathrm{ml}$ and $30 \mathrm{ng} / \mathrm{ml}$ not included) denoted vitamin D insufficiency, and $\geq 30 \mathrm{ng} / \mathrm{ml}$ denoted vitamin D sufficiency. To evaluate the effects of vitamin D deficiency and simplify the interpretation of data, we combined vitamin $\mathrm{D}$ insufficiency and sufficiency as the "group with $25(\mathrm{OH}) \mathrm{D} 3>20 \mathrm{ng} / \mathrm{ml}$," while vitamin D deficiency as the "group with $25(\mathrm{OH}) \mathrm{D} 3 \leq 20 \mathrm{ng} / \mathrm{ml}$." According to the sun exposure and latitude of South China, we divided the whole year into two periods marking the period with high sun exposure (from April to September) and low sun exposure (from October to March), which might influence the result of serum levels of $25(\mathrm{OH}) \mathrm{D} 3$. As for disease activity, $\mathrm{CDAI}<150$ denoted clinical remission while $\mathrm{CDAI} \geq 150$ denoted clinical activity. Only when CDAI was not available was HBI applied for the assessment of disease activity, with $\mathrm{HBI}>4$ denoting disease activity. In the present study, the disease activity of 18 patients was assessed using HBI. Furthermore, SESCD $\leq 2$ denoted mucosal healing including complete $(\mathrm{SESCD}=0)$ and incomplete $(\mathrm{SESCD}=1$ or 2) healing [28].

2.3. Data Analysis. IMB SPSS, version 22.0 (IBM Corporation, Armonk, NY), was used for data analysis. Discrete data were reported as frequency and percentage, using a chi-square test or Fisher's exact test for comparison. The continuous variables which were normally distributed were expressed as the mean and standard deviation (SD) while non-normally distributed ones as the median and interquartile range (IQR), using an independent sample $t$-test or Mann-Whitney $U$ test for comparison as appropriate. Spearman rank correlation analysis was used for investigating the association between 25(OH)D3 and CDAI and SESCD as well as CRP, ESR, PLT, Hb, and ALB. A chi-square test was used for comparing the percentage of corticosteroid, immunomodulator, infliximab use, and IBD-related bowel surgery within one year after follow-up. The time needed for IBDrelated hospital admission, abdominal imaging, and endoscopy in the half, one, and two years after follow-up were 
TABLe 1: Demographic and clinical characteristics.

\begin{tabular}{|c|c|c|c|}
\hline & Group with $25(\mathrm{OH}) \mathrm{D} 3 \leq 20 \mathrm{ng} / \mathrm{ml} N=286$ & Group with $25(\mathrm{OH}) \mathrm{D} 3>20 \mathrm{ng} / \mathrm{ml} N=60$ & $P$ \\
\hline Gender, $n(\%)$ & & & 0.005 \\
\hline Male & $197(68.9 \%)$ & $52(86.7 \%)$ & \\
\hline Female & $89(31.1 \%)$ & $8(13.3 \%)$ & \\
\hline Median age, years (IQR) & $26(20-35)$ & $27(21-44)$ & 0.212 \\
\hline Median disease duration, years (IQR) & $2.0(0.5-4.4)$ & $1.5(0.5-5.2)$ & 0.741 \\
\hline Disease location, $n(\%)$ & & & 0.790 \\
\hline $\mathrm{L} 1$ & $64(22.4 \%)$ & $10(16.7 \%)$ & \\
\hline $\mathrm{L} 2$ & $34(11.9 \%)$ & $7(11.7 \%)$ & \\
\hline L3 & $169(59.1 \%)$ & $39(65.0 \%)$ & \\
\hline $\mathrm{L} 4$ & $19(6.4 \%)$ & $4(6.7 \%)$ & \\
\hline Disease behavior, $n(\%)$ & & & 0.308 \\
\hline $\mathrm{B} 1$ & $184(64.3 \%)$ & $45(75.0 \%)$ & \\
\hline B2 & $69(24.1 \%)$ & $9(15.0 \%)$ & \\
\hline B3 & $40(14.0 \%)$ & $8(13.3 \%)$ & \\
\hline Perianal lesions, $n(\%)$ & $93(32.5 \%)$ & $20(33.3 \%)$ & 0.902 \\
\hline Extraintestinal manifestations, $n(\%)$ & $42(14.7 \%)$ & $11(18.3 \%)$ & 0.476 \\
\hline Previous bowel surgery, $n$ (\%) & $45(15.7 \%)$ & $15(25.0 \%)$ & 0.085 \\
\hline Previous resection of terminal ileum, $n$ (\%) & $38(13.3 \%)$ & $12(20.0 \%)$ & 0.179 \\
\hline \multicolumn{4}{|l|}{ Previous medications, $n(\%)$} \\
\hline 5-Aminosalicylic acid & $120(42.0 \%)$ & $25(41.7 \%)$ & 0.967 \\
\hline Corticosteroids & $42(14.7 \%)$ & $8(13.3 \%)$ & 0.787 \\
\hline Azathioprine/6-mercaptopurine & $22(7.7 \%)$ & $7(11.7 \%)$ & 0.312 \\
\hline Methotrexate & $1(0.3 \%)$ & $0(0.0 \%)$ & 0.646 \\
\hline Thalidomide & $8(2.8 \%)$ & $2(3.3 \%)$ & 0.822 \\
\hline Infliximab & $6(2.1 \%)$ & $2(3.3 \%)$ & 0.563 \\
\hline Sun exposure & & & 0.886 \\
\hline Low (from October to March) & $124(43.4 \%)$ & $27(45.0 \%)$ & \\
\hline High (from April to September) & $162(56.6 \%)$ & $33(55.0 \%)$ & \\
\hline
\end{tabular}

According to the Montreal classification: L1, terminal ileum; L2, colon; L3, ileocolon; L4, UPG; B1, nonstricturing nonpenetrating; B2, stricturing, B3, penetrating.

compared by Mann-Whitney $U$ tests. Logistic Regression was used to establish the new predictive model. The areas under the receiver-operating characteristic (ROC) curves (AUCs) were used to figure out the predictive efficiency of $-25(\mathrm{OH}) \mathrm{D} 3, \mathrm{CRP}, \mathrm{ESR}$, and the new model of $-\left(5^{*} 25(\mathrm{OH})\right.$ $\left.\mathrm{D} 3+2^{*} \mathrm{Hb}\right)+\mathrm{ESR}$ for active CD. A $Z$ test was used for comparing the differences in the AUCs of the ROC between different biomarkers. A nomogram was established based on serum parameters for predicting active disease. All statistical tests were performed 2 -tailed with $P<0.05$ denoting a statistical significance.

2.4. Ethical Considerations. The hospital's institutional review board approved the protocol, and every patient in this study provided written informed consent.

\section{Results}

3.1. Demographics and Clinical Characteristics. A total of $346 \mathrm{CD}$ patients with serum 25(OH)D3 levels were enrolled in two groups with one group with $25(\mathrm{OH}) \mathrm{D} 3 \leq 20 \mathrm{ng} / \mathrm{ml}$ $(n=286)$ and the other with 25(OH)D3 $>20 \mathrm{ng} / \mathrm{ml}(n=60)$. Overall, only $3.2 \%(n=11)$ patients had vitamin D sufficiency. The median level of serum $25(\mathrm{OH}) \mathrm{D} 3$ was $12.0 \mathrm{ng} /$ $\mathrm{ml}$ (IQR: $8.0-17.0 \mathrm{ng} / \mathrm{ml}$ ). There was no difference in sun exposure between the two groups $(P=0.886)$. Data on demographics and clinical features of both groups are summarized in Table 1. Except for the higher proportion of male patients in the group with $25(\mathrm{OH}) \mathrm{D} 3>20 \mathrm{ng} / \mathrm{ml}(86.7 \%$ vs. $68.9 \%$, $P=0.005)$, other clinical characteristics including age, disease duration, location, behavior, perianal lesions, extraintestinal manifestations, previous bowel surgery, and medication were of no difference between the two groups.

The levels of ESR, CRP, and PLT were significantly higher in patients in the group with $25(\mathrm{OH}) \mathrm{D} 3 \leq 20 \mathrm{ng} /$ $\mathrm{ml}$ compared with others (40.0 [IQR: $21.0-62.3$ ] $\mathrm{mm} / \mathrm{h}$ vs. 28.0 [IQR: $13.5-48.8$ ] $\mathrm{mm} / \mathrm{h}, P=0.004 ; 20.6$ [IQR: 5.546.9] $\mathrm{mg} / \mathrm{dl}$ vs. 11.7 [IQR: $1.9-24.2] \mathrm{mg} / \mathrm{dl}, P=0.005 ; 341.5$ [IQR: $266.5-413.3$ ] $* 10^{9} / 1$ vs. 279.0 [IQR: $224.0-338.8$ ] $*$ $10^{9} / 1, P<0.001$, respectively) (see Table 2 ). Furthermore, the levels of $\mathrm{Hb}$ and ALB were lower in patients with $25(\mathrm{OH}) \mathrm{D} 3 \leq 20 \mathrm{ng} / \mathrm{ml}$ (110.0 [IQR: 93.8-125.0] g/l vs. 127.0 
TABLE 2: Characteristics of laboratory parameters.

\begin{tabular}{lccc}
\hline & Group with $25(\mathrm{OH}) \mathrm{D} 3 \leq 20 \mathrm{ng} / \mathrm{ml} N=286$ & Group with $25(\mathrm{OH}) \mathrm{D} 3>20 \mathrm{ng} / \mathrm{ml}=60$ & $P$ \\
\hline $25(\mathrm{OH}) \mathrm{D} 3, \mathrm{ng} / \mathrm{ml}(\mathrm{IQR})$ & $11.0(7.0-14.0)$ & $23.5(21.0-27.8)$ & $28.0(13.5-48.8)$ \\
$\mathrm{ESR}, \mathrm{mm} / \mathrm{h}(\mathrm{IQR})$ & $40.0(21.0-62.3)$ & $11.7(1.9-24.2)$ & 0.001 \\
$\mathrm{CRP}, \mathrm{mg} / \mathrm{dl}(\mathrm{IQR})$ & $20.6(5.5-46.9)$ & $6.6(5.4-8.7)$ & 0.005 \\
$\mathrm{WBC}, * 10^{9}(\mathrm{IQR})$ & $7.3(5.7-9.4)$ & $279.0(224.0-338.8)$ & 0.089 \\
$\mathrm{PLT}, * 10^{9} / \mathrm{l}(\mathrm{IQR})$ & $341.5(266.5-413.3)$ & $127.0(112.5-139.5)$ & $<0.001$ \\
$\mathrm{Hb}, \mathrm{g} / \mathrm{l}(\mathrm{IQR})$ & $110.0(93.8-125.0)$ & $38.0( \pm 5.1)$ & $<0.001$ \\
$\mathrm{ALB}, \mathrm{g} / \mathrm{l}(\mathrm{mean} \pm \mathrm{SD})$ & $34.6( \pm 5.5)$ & $<0.001$ \\
\hline
\end{tabular}

ESR, erythrocyte sedimentation rate; CRP, C-reactive protein; WBC, white blood cell count; PLT, platelet counts; Hb, hemoglobin; ALB, albumin.

TABle 3: Correlation of serum 25(OH)D3 levels with CDAI and several parameters.

\begin{tabular}{lcc}
\hline & $r_{\mathrm{s}}$ & $P$ \\
\hline CDAI score $(N=328)$ & -0.608 & $<0.001$ \\
HBI score $(N=18)$ & -0.516 & 0.028 \\
SESCD score $(N=282)$ & -0.290 & $<0.001$ \\
$\operatorname{BMI}(N=326)$ & 0.176 & 0.001 \\
$\operatorname{ESR}(N=346)$ & -0.205 & $<0.001$ \\
CRP $(N=346)$ & -0.219 & $<0.001$ \\
WBC $(N=346)$ & -0.089 & 0.097 \\
$\operatorname{PLT}(N=346)$ & -0.274 & $<0.001$ \\
$\operatorname{Hb}(N=346)$ & 0.370 & $<0.001$ \\
ALB $(N=346)$ & 0.351 & $<0.001$ \\
\hline
\end{tabular}

$r_{\mathrm{s}}$, correlation coefficient for Spearman correlation; CDAI, Crohn's Disease Activity Index; BMI, body mass index; SESCD, Simplified Endoscopic Score for Crohn's Disease; ESR, erythrocyte sedimentation rate; CRP, Creactive protein; WBC, white blood cell count; PLT, platelet count; $\mathrm{Hb}$, hemoglobin; ALB, albumin.

[IQR: 112.5-139.5] g/l, $P<0.001 ; 34.6[ \pm 5.5] \mathrm{g} / \mathrm{l}$ vs. 38.0 $[ \pm 5.1] \mathrm{g} / \mathrm{l}, P<0.001$, respectively). No significant difference was found in WBC between the two groups.

3.2. Correlation of 25(OH)D3 Levels with Disease Activity and Inflammatory Markers. To compare the clinical and endoscopic activity of $\mathrm{CD}$, participants were divided into active disease and clinical remission according to the score of CDAI or HBI. Meanwhile, patients with available endoscopic results $(n=282)$ were categorized into mucosal healing and mucosal activity according to the score of SESCD. The results of these analyses showed that patients with $25(\mathrm{OH}) \mathrm{D} 3>20 \mathrm{ng} / \mathrm{ml}$ were more likely to be in clinical remission and mucosal healing than patients in another group $(12.9 \%$ vs. $48.3 \%, P<0.001 ; 12.7 \%$ vs. $28.9 \%, P=$ 0.005 , respectively). Patients in clinical remission had higher 25(OH)D3 levels than others (19.0 [IQR: 14.0-22.0] ng/ml vs. 10.5 [IQR: $7.0-15.8] \mathrm{ng} / \mathrm{ml}, P<0.001)$.

The serum 25(OH)D3 levels were strongly correlated with the CDAI $\left(r_{\mathrm{s}}=-0.608, P<0.001\right)$. For the 18 patients whose disease activity was assessed by HBI, the correlation was similar but weaker than CDAI $\left(r_{\mathrm{s}}=-0.516, P=0.028\right)$, which may probably be due to the small sample size. Correlation between levels of 25(OH)D3 and the SESCD score $\left(r_{\mathrm{s}}=-0.290\right)$, BMI $\left(r_{\mathrm{s}}=0.176\right)$, ESR $\left(r_{\mathrm{s}}=-0.205\right)$,
$\mathrm{CRP} \quad\left(r_{\mathrm{s}}=-0.219\right), \operatorname{PLT} \quad\left(r_{\mathrm{s}}=-0.274\right), \mathrm{Hb} \quad\left(r_{\mathrm{s}}=0.370\right)$, and ALB $\left(r_{\mathrm{s}}=0.351\right)$ was weaker but of statistical significance (all $P<0.05$ ) (see Table 3 ). In our study, the CDAI score was poorly correlated with the SESCD score $\left(r_{\mathrm{s}}=0.303, P<0.001\right)$.

Correlation between ESR and CRP and the CDAI score was also determined in this study. ESR and CRP were positively correlated with the CDAI score $\left(r_{s}=0.391, P=\right.$ $0.001 ; r_{s}=0.392, P<0.001$, respectively). The absolute value of the correlation coefficient $\left(r_{s}\right)$ between 25(OH)D3 levels and the CDAI score was significantly higher than that of ESR and CRP (both $P=0.002$ ).

3.3. Receiver-Operating Characteristic Analysis. Receiveroperating characteristic analysis (see Table 4 and Figure 1) showed that $-25(\mathrm{OH}) \mathrm{D} 3$ had a higher diagnostic accuracy for active disease with an AUC of 0.804 compared to CRP (AUC $=0.693, P=0.0082$ ) and ESR (AUC $=0.713, P=$ $0.0245)$. The optimal threshold of $-25(\mathrm{OH}) \mathrm{D} 3$ for active disease was $-12.5 \mathrm{ng} / \mathrm{ml}$, with $61.1 \%$ sensitivity and $87.9 \%$ specificity. There was no difference in AUC between CRP and $\operatorname{ESR}(P=0.6587)$.

3.4. A New Model Based on 25(OH)D3 and Nomogram. For better prediction, we set up a new model based on 25(OH)D3 and other serum parameters using Logistic Regression. Since CRP and PLT were highly relevant to ESR with $r_{\mathrm{s}}$ of 0.594 and 0.530 , respectively $(P<0.001)$, they were not included in Logistic Regression. As shown in Table 5, 25(OH)D3 $(P<0.001), \mathrm{Hb}(P<0.001)$, and ESR $(P=0.013)$ were related to disease activity with the $B$ coefficient of $-0.132,-0.046$, and 0.022 , respectively. To simplify the calculation, we used $-\left(5^{*} 25(\mathrm{OH}) \mathrm{D} 3+2 * \mathrm{Hb}\right)+\mathrm{ESR}$ as a new predictor for disease activity with an AUC of 0.879 (see Table 4 and Figure 1), significantly higher than those of $-25(\mathrm{OH}) \mathrm{D} 3(P=0.0199)$, CRP $(P<0.0001)$, ESR $(P<0.0001)$, and $-\mathrm{Hb}(P=0.0396)$. The optimal threshold value was -272.5 with $72.1 \%$ sensitivity and $92.4 \%$ specificity. Figure 2 shows the nomogram using serum parameters for prediction. Internal validation showed a c-index of 0.882 with $73.2 \%$ sensitivity and $90.9 \%$ specificity.

\section{Discussion}

In this study, we found that $75.1 \%$ of CD patients suffered from vitamin $\mathrm{D}$ deficiency, as only $3.2 \%$ of them had 
TABLE 4: Receiver-operating characteristic analysis for active disease.

\begin{tabular}{|c|c|c|c|c|c|c|}
\hline & AUC & $95 \%$ CI of AUC & $P$ & Optimal threshold value & Sensitivity & Specificity \\
\hline$-25(\mathrm{OH}) \mathrm{D} 3$ & 0.804 & $0.753-0.854$ & $<0.001$ & -12.5 & 0.611 & 0.879 \\
\hline CRP & 0.693 & $0.628-0.758$ & $<0.001$ & 27.19 & 0.468 & 0.879 \\
\hline ESR & 0.713 & $0.653-0.773$ & $<0.001$ & 46.5 & 0.454 & 0.894 \\
\hline$-\mathrm{Hb}$ & 0.816 & $0.768-0.864$ & $<0.001$ & -121.5 & 0.725 & 0.803 \\
\hline$-\left(5^{*} 25(\mathrm{OH}) \mathrm{D} 3+2^{*} \mathrm{Hb}\right)+\mathrm{ESR}$ & 0.879 & $0.841-0.916$ & $<0.001$ & -518.5 & 0.682 & 0.924 \\
\hline
\end{tabular}

AUC, areas under the receiver-operating characteristic curves; ESR, erythrocyte sedimentation rate; CRP, C-reactive protein; Hb, hemoglobin.

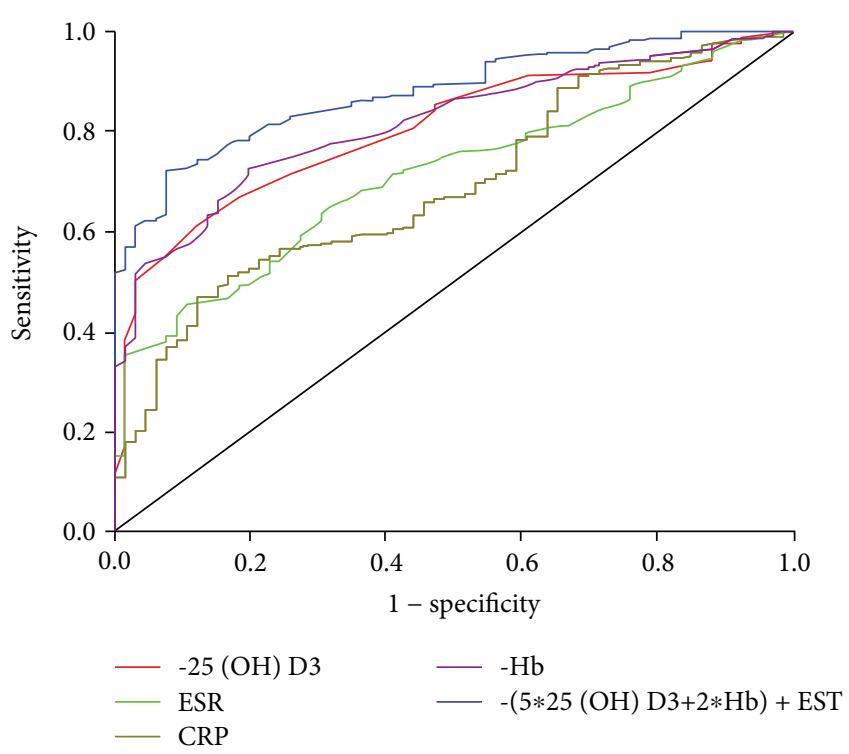

FIGURE 1: Receiver-operating characteristic curves of various parameters for active disease. The areas under the receiveroperating characteristic curve were 0.804 and 0.816 for $-25(\mathrm{OH}) \mathrm{D} 3$ and $-\mathrm{Hb}$, respectively, higher than those of CRP (0.693) and ESR (0.713) for distinguishing active from inactive Crohn's disease with $P<0.005$. The areas under the receiver-operating characteristic curve for $-\mathrm{Hb}$ vs. $-\left(5^{*} 25(\mathrm{OH}) \mathrm{D} 3+2^{*} \mathrm{Hb}\right)+\mathrm{ESR}$ were higher than those of $-25(\mathrm{OH}) \mathrm{D} 3$ and $-\mathrm{Hb}$ with $P<0.005$.

sufficient vitamin D levels. The percentage of patients with vitamin $\mathrm{D}$ deficiency was higher than that reported in most previous studies, ranging from $31 \%$ to $50 \%$, while the percentage of vitamin D-sufficient patients was much lower than the $35 \%-73 \%$ published in a previous report [16]. However, the results were similar to those of a study on Chinese people, with $67.8 \%$ vitamin $\mathrm{D}$ deficiency and $3.2 \%$ sufficiency in $\mathrm{CD}$ patients [25]. Despite no previous study on the differences in vitamin D between Chinese and Caucasian CD patients, one study by $\mathrm{Fu}$ et al. pointed out that the prevalence of vitamin $\mathrm{D}$ deficiency in South Asian CD patients was higher than that in Caucasian patients [29]. Thus, the higher proportion of vitamin $\mathrm{D}$ deficiency in Chinese patients may result from ethnic difference.

Although possible mechanisms of vitamin D deficiency are still unclear, they may include inadequate sun exposure, insufficient dietary intake, absorption dysfunction, impaired conversion of vitamin $\mathrm{D}$ activation, increased catabolism, and excretion [16]. Since one of the major sources of vitamin $\mathrm{D}$ is absorption by the small intestine, disturbances in the intestinal function may mainly contribute to vitamin $\mathrm{D}$ deficiency in $\mathrm{CD}$ patients. However, in this study, no significant differences in $25(\mathrm{OH}) \mathrm{D} 3$ levels were found either between different disease locations or between with and without previous small intestinal surgery. So malabsorption in the small intestine was also less likely to be the major factor.

Despite vitamin $\mathrm{D}$ being a marker of nutrient status in CD patients [17], only few studies have noted the correlation between vitamin $\mathrm{D}$ status and BMI in CD patients $[30,31]$. Pallav et al.'s study noted a significant association between $\mathrm{BMI}$ and vitamin $\mathrm{D}(P=0.0110)$, indicating that $\mathrm{BMI}>30 \mathrm{~kg} / \mathrm{m}^{2}$ was a predictor of vitamin D deficiency [31]. Conversely, the other study found no such association [30]. However, these studies were limited by small sample size or absence of subgroup analysis of CD patients. To determine the association between vitamin $\mathrm{D}$ and nutrient status, we compared the values of BMI, $\mathrm{Hb}$, and ALB in different groups and performed correlation analysis among them. The results showed that patients with lower vitamin $\mathrm{D}$ tend to have lower BMI, Hb, and ALB levels. Moreover, weak but significant positive correlations were found between 25(OH)D3 and BMI, as well as negative correlations between 25(OH)D3 and $\mathrm{Hb}$ and ALB. According to these results, we can conclude that vitamin D levels are associated with overall nutrient status in CD patients.

Vitamin D plays an important role in the immune system, especially in patients with CD [32], but previous studies have failed to demonstrate whether the vitamin D status is associated with inflammatory markers like CRP and ESR. Several studies have shown a negative association between $25(\mathrm{OH}) \mathrm{D} 3$ and inflammatory markers $[33,34]$. A research on a cohort of $201 \mathrm{CD}$ patients in Canada stated that CRP was significantly lower in patients with vitamin $\mathrm{D}$ deficiency [33]. Other studies did not reach such an agreement $[19,20$, $35,36]$. A study conducted by Garg et al. found a correlation between 25(OH)D3 levels and calprotectin with Pearson's $r=-0.35$ but no correlation with systemic inflammatory markers like CRP and PLT. The authors noted that vitamin D status was associated with only mucosal inflammatory markers but not systemic ones. Because of the conflicting results in previous studies, a study with a larger sample size was needed. In our study, we demonstrated significant negative correlations between $25(\mathrm{OH}) \mathrm{D} 3$ and inflammatory biomarkers, which implied that vitamin $\mathrm{D}$ may contribute to systemic inflammation in CD and is an efficient biomarker for the estimation of inflammation. 
TABLE 5: Logistic Regression for disease activity.

\begin{tabular}{|c|c|c|c|c|}
\hline \multirow{2}{*}{ Factors } & \multicolumn{2}{|c|}{ Univariate analysis } & \multicolumn{2}{|c|}{ Multivariate analysis } \\
\hline & OR $(95 \% \mathrm{CI})$ & $P$ & OR $(95 \% \mathrm{CI})$ & $P$ \\
\hline $25(\mathrm{OH}) \mathrm{D} 3$ & $0.865(0.829-0.903)$ & $<0.001$ & $0.876(0.832-0.923)$ & $<0.001$ \\
\hline ESR & $1.036(1.022-1.051)$ & $<0.001$ & $1.022(1.005-1.040)$ & 0.013 \\
\hline WBC & $1.075(0.968-1.193)$ & 0.177 & - & - \\
\hline $\mathrm{Hb}$ & $0.934(0.916-0.952)$ & $<0.001$ & $0.955(0.934-0.975)$ & $<0.001$ \\
\hline ALB & $0.826(0.776-0.879)$ & $<0.001$ & $0.937(0.863-1.017)$ & 0.121 \\
\hline
\end{tabular}

ESR, erythrocyte sedimentation rate; CRP, C-reactive protein; WBC, white blood cell count; PLT, platelet count; Hb, hemoglobin; ALB, albumin.

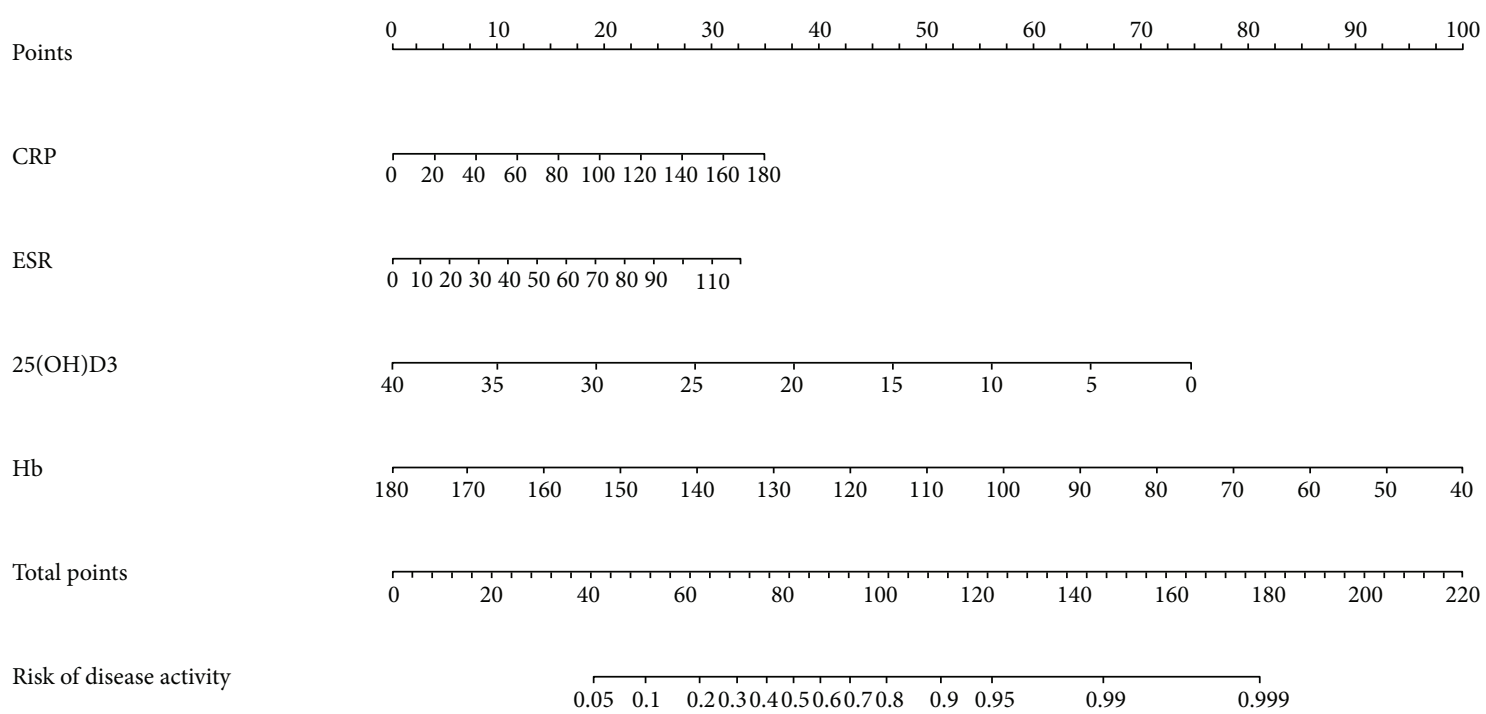

FIGURE 2: Nomogram for predicting active CD based on 25(OH)D3 and other serum parameters. The c-index of this nomogram was 0.882 with a sensitivity of $73.2 \%$ and a specificity of $90.9 \%$.

More importantly, our results confirmed a moderate negative association between $25(\mathrm{OH}) \mathrm{D} 3$ and disease activity, supporting the study on Chinese patients concerning the correlation, but with a higher absolute value of the correlation coefficient $(-0.608$ vs. -0.285$)$ [24]. This value was also higher than that reported in the recent meta-analysis on 6 studies [37]. But our result was similar to another study focusing on Chinese patients with a coefficient of 0.582 [26]. Furthermore, we found that the correlation between $25(\mathrm{OH}) \mathrm{D} 3$ and CDAI was much higher than that of CRP and ESR. Consequently, the AUC of $-25(\mathrm{OH}) \mathrm{D} 3$ in ROC analysis for Crohn's disease activity was much higher than the AUCs of CRP and ESR, which indicate that $-25(\mathrm{OH}) \mathrm{D} 3$ might be a better predictor of disease activity. In addition, we calculated $-\left(5^{*} 25(\mathrm{OH}) \mathrm{D} 3+2^{*} \mathrm{Hb}\right)+\mathrm{ESR}$ as a new factor to enhance the predictive efficiency of vitamin $\mathrm{D}$ for $\mathrm{CD}$ activity, which was significantly superior to $-25(\mathrm{OH}) \mathrm{D} 3,-\mathrm{Hb}, \mathrm{CRP}$, and ESR, with both higher sensitivity and specificity.

There are some limitations in this study. First, in this single-center retrospective study, most patients inhabited in South China and might not fully represent the overall CD patients in China. Second, the time of follow-up was diverse in different patients. Lack of data on the daily sunlight exposure in different individuals may have caused an inevitable bias in serum levels of $25(\mathrm{OH}) \mathrm{D} 3$, as the influence of this factor could not be eliminated in the analysis [38]. Furthermore, some patients with a short follow-up time could be eliminated at the expense of reducing the sample size. Another potential limitation was that the predictive efficacy of markers including $-25(\mathrm{OH}) \mathrm{D} 3$ and $-\left(5^{*} 25(\mathrm{OH}) \mathrm{D} 3+2^{*}\right.$ $\mathrm{Hb})+\mathrm{ESR}$ might not be precise, as we used a score of $\mathrm{CDAI} \geq 150$ to estimate active disease without a gold standard. In addition, we were unable to collect data on intestinal inflammatory biomarkers like fecal calprotectin for demonstrating the association between $25(\mathrm{OH}) \mathrm{D} 3$ and intestinal inflammation. We could not use the SESCD score to set up a predictive model either because the number of patients with complete mucosal healing was so limited that it could not meet the need of an effective nomogram. Also, according to the original article presenting the SESCD score, the SESCD score is limited because it is calculated only with the disease behavior under colonoscopy but omits the clinical manifestations, but disease activity is not necessarily reflected on the mucosa [28]. Finally, the CDAI score was correlated with SESCD with a minor $r_{s}$ of 0.303 , which was consistent with a previous study [39] showing that CDAI is not a reliable measure of the underlying mucosal inflammation. So the 
SESCD score is not a suitable standard for disease activity in the predictive model. We also lacked the data on the life quality of patients.

In conclusion, despite some inevitable limitations, our study confirms the correlation between vitamin $\mathrm{D}$ and the activity of Crohn's disease. We suggest that the correlation between 25(OH)D3 and CDAI might be stronger in Chinese patients. $25(\mathrm{OH}) \mathrm{D} 3$ is an efficient marker for estimating systemic inflammation and a better marker for evaluating disease activity than CRP and ESR. Besides, we provide the possibility of using $-25(\mathrm{OH}) \mathrm{D} 3$ and $-\left(5^{*} 25(\mathrm{OH}) \mathrm{D} 3+\right.$ $2 * \mathrm{Hb})+\mathrm{ESR}$ as predictors for active Crohn's disease, which might be applied in the clinic for distinguishing active diseases. However, these findings need to be verified using further large-scale investigations.

\section{Data Availability}

The data were stored in http://ibdcenter.kangzhe.net/ ibdcenter/Admin/Login.aspx.

\section{Disclosure}

An earlier version of this abstract has been published at The $18^{\text {th }}$ Congress of Gastroenterology China, 2018.

\section{Conflicts of Interest}

The authors have no conflicts of interest to disclose.

\section{Authors' Contributions}

Sinan Lin and Ying Wang contributed equally to the work.

\section{Acknowledgments}

We appreciate the help of all the members in the IBD-MDT group of the First Affiliated Hospital of Sun Yat-sen University for collecting data and clinical care of the patients. We also thank all the patients for their kind participation. This project was supported by grants from the National Natural Science Foundation of China (\#81670498, \#81630018, and \#81870374), Pearl River S and T Nova Program of Guangzhou (\#201610010126), Guangdong Provincial Department of Science and Technology (\#2016A020214006 and \#2017A030306021), and Science and Technology Innovation Young Talents of Guangdong Special Support Plan (2016TQ03R296).

\section{References}

[1] S. B. Hanauer, "Inflammatory bowel disease: epidemiology, pathogenesis, and therapeutic opportunities," Inflammatory Bowel Diseases, vol. 12, Supplement 1, pp. S3-S9, 2006.

[2] H. Wang, K. Chao, S. C. Ng et al., "Pro-inflammatory miR-223 mediates the cross-talk between the IL23 pathway and the intestinal barrier in inflammatory bowel disease," Genome Biology, vol. 17, no. 1, p. 58, 2016.

[3] T. Feng, B. Chen, L. Li et al., "Serum interleukin 9 levels predict disease severity and the clinical efficacy of infliximab in patients with Crohn's disease," Inflammatory Bowel Diseases, vol. 23, no. 10, pp. 1817-1824, 2017.

[4] H. S. P. de Souza and C. Fiocchi, "Immunopathogenesis of IBD: current state of the art," Nature Reviews. Gastroenterology \& Hepatology, vol. 13, no. 1, pp. 13-27, 2016.

[5] O. H. Nielsen, L. Rejnmark, and A. C. Moss, "Role of vitamin $\mathrm{D}$ in the natural history of inflammatory bowel disease," Journal of Crohn's \& Colitis, vol. 12, no. 6, pp. 742-752, 2018.

[6] M. F. Holick, "Vitamin D deficiency," The New England Journal of Medicine, vol. 357, no. 3, pp. 266-281, 2007.

[7] C. J. Rosen, "Clinical practice. Vitamin D insufficiency," The New England Journal of Medicine, vol. 364, no. 3, pp. 248254, 2011.

[8] M. Hewison, "Vitamin D and the immune system: new perspectives on an old theme," Endocrinology and Metabolism Clinics of North America, vol. 39, no. 2, pp. 365-379, 2010.

[9] U. Nydegger, T. Lung, L. Risch, M. Risch, P. Medina Escobar, and T. Bodmer, "Inflammation thread runs across medical laboratory specialities," Mediators of Inflammation, vol. 2016, Article ID 4121837, 10 pages, 2016.

[10] M. Bendix-Struve, L. E. Bartels, J. Agnholt, A. Dige, S. P. Jørgensen, and J. F. Dahlerup, "Vitamin D3 treatment of Crohn's disease patients increases stimulated T cell IL-6 production and proliferation," Alimentary Pharmacology \& Therapeutics, vol. 32, no. 11-12, pp. 1364-1372, 2010.

[11] T. T. Wang, B. Dabbas, D. Laperriere et al., "Direct and indirect induction by 1,25-dihydroxyvitamin $\mathrm{D}_{3}$ of the NOD2/ CARD15-defensin $\beta 2$ innate immune pathway defective in Crohn disease," The Journal of Biological Chemistry, vol. 285, no. 4, pp. 2227-2231, 2010.

[12] L. E. Bartels, S. P. Jørgensen, M. Bendix et al., "25-Hydroxy vitamin D3 modulates dendritic cell phenotype and function in Crohn's disease," Inflammopharmacology, vol. 21, no. 2, pp. 177-186, 2013.

[13] S. Dionne, M. R. Calderon, J. H. White et al., "Differential effect of vitamin D on NOD2- and TLR-induced cytokines in Crohn's disease," Mucosal Immunology, vol. 7, no. 6, pp. 1405-1415, 2014.

[14] A. N. Ananthakrishnan, H. Khalili, L. M. Higuchi et al., "Higher predicted vitamin D status is associated with reduced risk of Crohn's disease," Gastroenterology, vol. 142, no. 3, pp. 482-489, 2012.

[15] J. L. Opstelten, S. S. M. Chan, A. R. Hart et al., "Prediagnostic serum vitamin D levels and the risk of Crohn's disease and ulcerative colitis in European populations: a nested casecontrol study," Inflammatory Bowel Diseases, vol. 24, no. 3, pp. 633-640, 2018.

[16] V. P. Mouli and A. N. Ananthakrishnan, "Review article: vitamin D and inflammatory bowel diseases," Alimentary Pharmacology \& Therapeutics, vol. 39, no. 2, pp. 125-136, 2014.

[17] A. D. Harries, R. Brown, R. V. Heatley, L. A. Williams, S. Woodhead, and J. Rhodes, "Vitamin D status in Crohn's disease: association with nutrition and disease activity," Gut, vol. 26, no. 11, pp. 1197-1203, 1985.

[18] A. Ulitsky, A. N. Ananthakrishnan, A. Naik et al., "Vitamin D deficiency in patients with inflammatory bowel disease: association with disease activity and quality of life," JPEN Journal of Parenteral and Enteral Nutrition, vol. 35, no. 3, pp. 308-316, 2011.

[19] M. Garg, O. Rosella, J. S. Lubel, and P. R. Gibson, “Association of circulating vitamin D concentrations with intestinal but not 
systemic inflammation in inflammatory bowel disease," Inflammatory Bowel Diseases, vol. 19, no. 12, pp. 2634-2643, 2013.

[20] M. Ham, M. S. Longhi, C. Lahiff, A. Cheifetz, S. Robson, and A. C. Moss, "Vitamin D levels in adults with Crohn's disease are responsive to disease activity and treatment," Inflammatory Bowel Diseases, vol. 20, no. 5, pp. 856-860, 2014.

[21] W. El-Matary, S. Sikora, and D. Spady, "Bone mineral density, vitamin $\mathrm{D}$, and disease activity in children newly diagnosed with inflammatory bowel disease," Digestive Diseases and Sciences, vol. 56, no. 3, pp. 825-829, 2011.

[22] A. D. Levin, V. Wadhera, S. T. Leach et al., "Vitamin D deficiency in children with inflammatory bowel disease," Digestive Diseases and Sciences, vol. 56, no. 3, pp. 830-836, 2011.

[23] A. Grunbaum, C. Holcroft, D. Heilpern et al., "Dynamics of vitamin $\mathrm{D}$ in patients with mild or inactive inflammatory bowel disease and their families," Nutrition Journal, vol. 12, no. 1, p. $145,2013$.

[24] B. Tan, P. Li, H. Lv et al., "Vitamin D levels and bone metabolism in Chinese adult patients with inflammatory bowel disease," Journal of Digestive Diseases, vol. 15, no. 3, pp. 116123, 2014

[25] S. L. Xia, X. X. Lin, M. D. Guo et al., "Association of vitamin D receptor gene polymorphisms and serum 25-hydroxyvitamin D levels with Crohn's disease in Chinese patients," Journal of Gastroenterology and Hepatology, vol. 31, no. 4, pp. 795-801, 2016.

[26] L. Ye, Z. Lin, J. Liu, and Q. Cao, "Vitamin D deficiency is associated with endoscopic severity in patients with Crohn's disease," Gastroenterology Research and Practice, vol. 2017, Article ID 4869718, 5 pages, 2017.

[27] M. S. Silverberg, J. Satsangi, T. Ahmad et al., "Toward an integrated clinical, molecular and serological classification of inflammatory bowel disease: report of a working party of the 2005 Montreal World Congress of Gastroenterology," Canadian Journal of Gastroenterology, vol. 19, Supplement A, pp. 5A-36A, 2005.

[28] M. Daperno, G. D'Haens, G. van Assche et al., "Development and validation of a new, simplified endoscopic activity score for Crohn's disease: the SES-CD," Gastrointestinal Endoscopy, vol. 60, no. 4, pp. 505-512, 2004.

[29] Y.-T. N. Fu, N. Chatur, C. Cheong-Lee, and B. Salh, "Hypovitaminosis D in adults with inflammatory bowel disease: potential role of ethnicity," Digestive Diseases and Sciences, vol. 57, no. 8, pp. 2144-8, 2012.

[30] S. O. Frigstad, M. Høivik, J. Jahnsen et al., "Vitamin D deficiency in inflammatory bowel disease: prevalence and predictors in a Norwegian outpatient population," Scandinavian Journal of Gastroenterology, vol. 52, no. 1, pp. 100-106, 2016.

[31] K. Pallav, D. Riche, W. L. May, P. Sanchez, and N. K. Gupta, "Predictors of vitamin D deficiency in inflammatory bowel disease and health: a Mississippi perspective," World Journal of Gastroenterology, vol. 23, no. 4, pp. 638-645, 2017.

[32] J. H. White, "Vitamin D deficiency and the pathogenesis of Crohn's disease," The Journal of Steroid Biochemistry and Molecular Biology, vol. 175, pp. 23-28, 2018.

[33] D. Alrefai, J. Jones, W. el-Matary et al., "The association of vitamin D status with disease activity in a cohort of Crohn's disease patients in Canada," Nutrients, vol. 9, no. 10, 2017.

[34] T. A. Kabbani, I. E. Koutroubakis, R. E. Schoen et al., “Association of vitamin D level with clinical status in inflammatory bowel disease: a 5-year longitudinal study," The American Journal of Gastroenterology, vol. 111, no. 5, pp. 712-719, 2016.

[35] S. Zullow, G. Jambaulikar, A. Rustgi, S. Quezada, and R. K. Cross, "Risk factors for vitamin D deficiency and impact of repletion in a tertiary care inflammatory bowel disease population," Digestive Diseases and Sciences, vol. 62, no. 8, pp. 2072 2078, 2017.

[36] S. P. Jørgensen, C. L. Hvas, J. Agnholt, L. A. Christensen, L. Heickendorff, and J. F. Dahlerup, "Active Crohn's disease is associated with low vitamin D levels," Journal of Crohn's \& Colitis, vol. 7, no. 10, pp. e407-e413, 2013.

[37] M. Sadeghian, P. Saneei, F. Siassi, and A. Esmaillzadeh, "Vitamin D status in relation to Crohn's disease: meta-analysis of observational studies," Nutrition, vol. 32, no. 5, pp. 505-514, 2016.

[38] L. Elizondo-Montemayor, E. C. Castillo, C. Rodríguez-López et al., "Seasonal variation in vitamin $\mathrm{D}$ in association with age, inflammatory cytokines, anthropometric parameters, and lifestyle factors in older adults," Mediators of Inflammation, vol. 2017, Article ID 5719461, 14 pages, 2017.

[39] L. Peyrin-Biroulet, W. Reinisch, J. F. Colombel et al., "Clinical disease activity, C-reactive protein normalisation and mucosal healing in Crohn's disease in the SONIC trial," Gut, vol. 63, no. 1, pp. 88-95, 2013. 


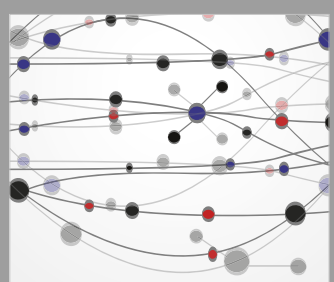

The Scientific World Journal
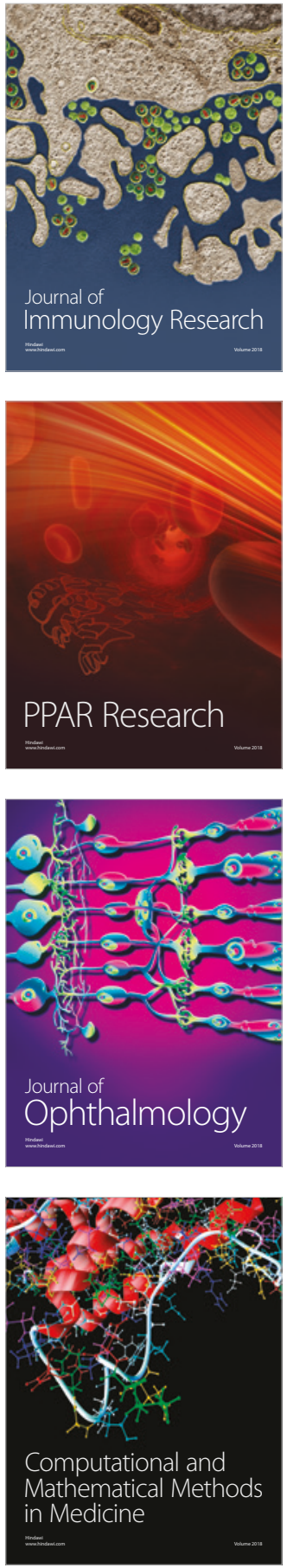

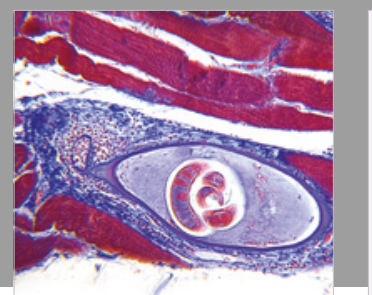

Gastroenterology Research and Practice

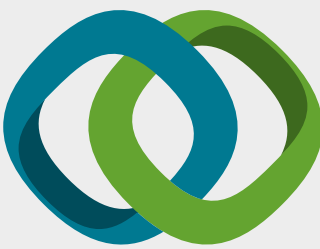

\section{Hindawi}

Submit your manuscripts at

www.hindawi.com
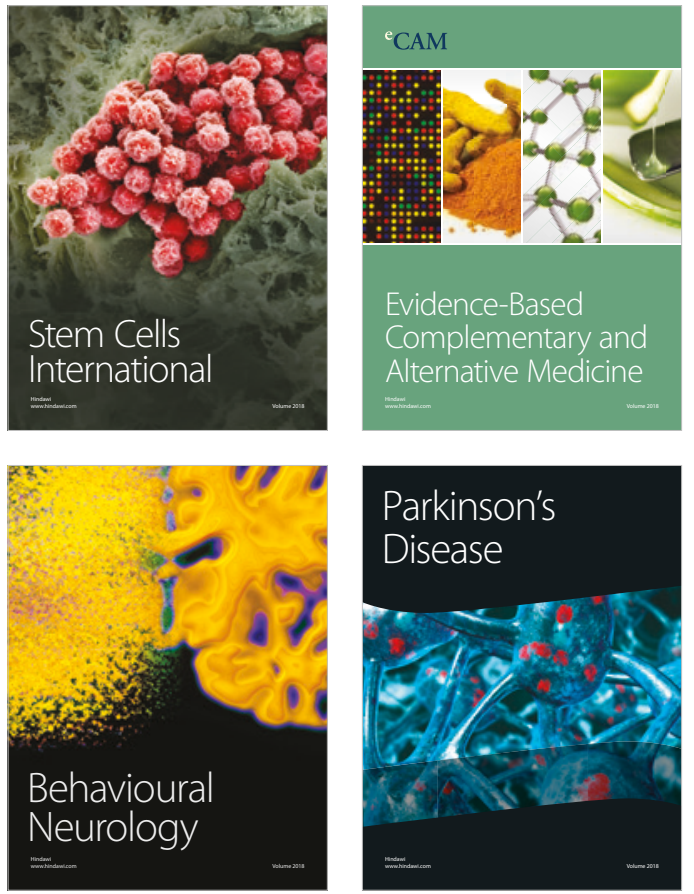

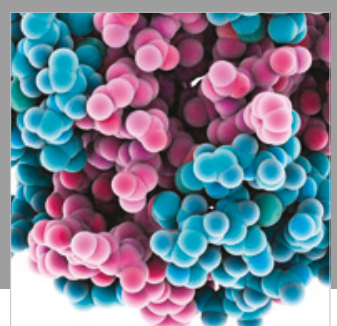

ournal of

Diabetes Research

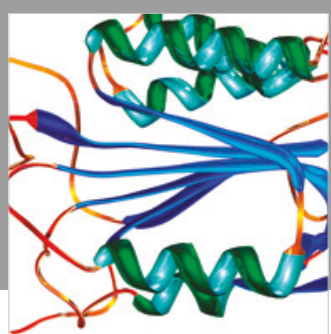

Disease Markers
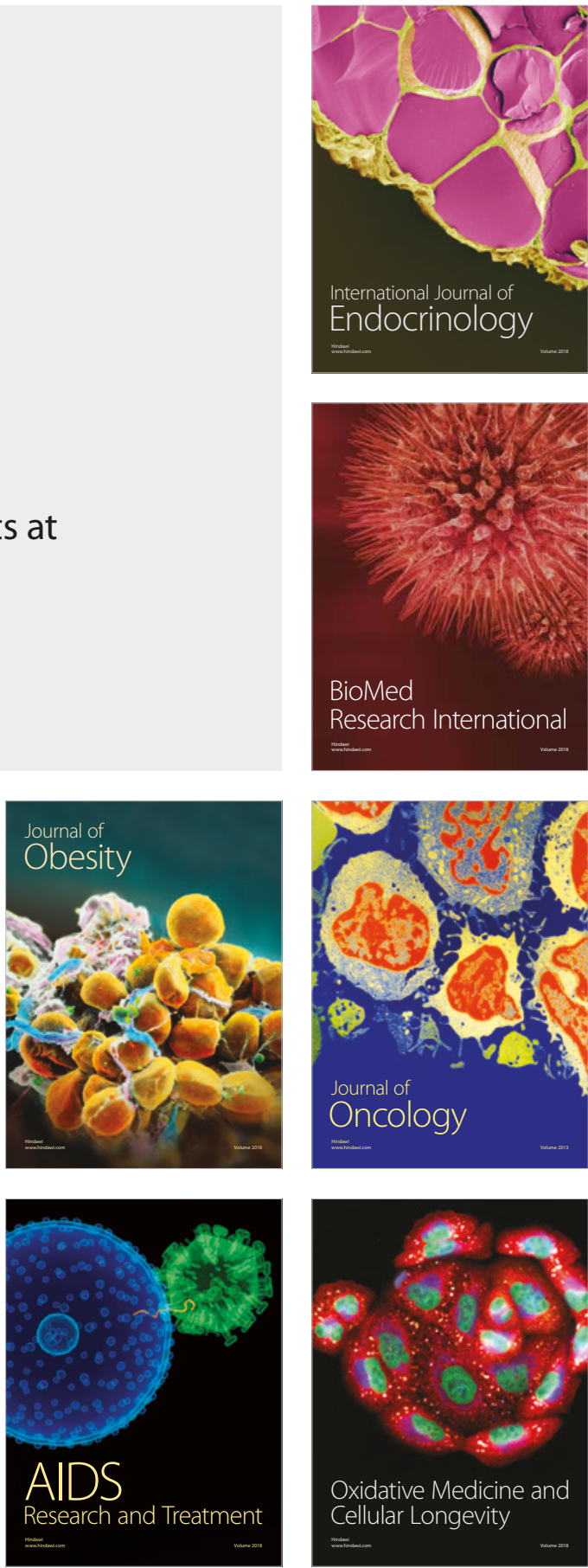